\section{Correlations between Some Horticultural Traits in Walnut}

\author{
Reza Amiri \\ Department of Agronomy and Crop Breeding Sciences, College of Abouraihan, \\ University of Tehran, P.C.: 33916 53755, Pakdasht, Tehran, Iran
}

Kourosh Vahdati ${ }^{1}$ and Somayeh Mohsenipoor

Department of Horticulture, College of Abouraihan, University of Tehran, P.C.: 33916 53755, Pakdasht, Tehran, Iran

Mohammad Reza Mozaffari
Agriculture and Natural Resources Research Center, Kerman, Iran

Charles Leslie

Department of Plant Sciences, University of California, Davis, One Shields Avenue, Davis CA 95616

Additional index words. blight, frost, nut, kernel, path analysis, stepwise regression

\begin{abstract}
Correlation and causal relationships among 21 horticultural traits were determined using 71 walnut genotypes selected from seven valleys in Kerman Province, Iran. Pearson's correlation coefficient was calculated. Kernel percentage and blight susceptibility were used as dependent variables in a stepwise regression model to determine predictor variables. Direct and indirect effects of each independent variable were calculated using path analysis. A highly significant correlation was observed between lateral bearing habit and yield. Lateral-bearing trees were also more susceptible to blight and winter cold than terminal bearers. Kernel and nut weights, shell thickness, and difficulty of extracting kernel halves were the most important traits accounting for kernel variation. Kernel weight and difficulty extracting kernel halves had the strongest positive direct effects and nut weight the most negative. Flowering habit, nut shape, and leafing date had positive direct effects on blight susceptibility, but the large residual effects suggest there are other important determinant traits for blight susceptibility, which were not considered in this study.
\end{abstract}

Persian walnut (Juglans regia L.), widely cultivated for nut production, is an ancient species (Fjellstrom and Parfitt, 1994; Vahdati, 2000) originating in areas of Central Asia, including Iran. Wild trees of this species are widely dispersed throughout Iran and provide a rich natural reservoir of walnut germplasm for developing improved genotypes. Kerman province has the greatest planted area of Persian walnuts under cultivation in Iran and also has the largest native walnut stands (Vahdati, 2000).

Knowledge of the relationship between nut and kernel characteristics and other tree traits can guide appropriate selection schemes for walnut breeding programs. Hansche et al. (1972) examined heritability and phenotypic correlations for 18 traits of walnut and found heritabilities above 0.80 for shell thickness, nut and kernel weights and dates of leafing, first pollen shed, pistil receptivity, and harvest. The heritability was above 0.39 for lateral

\footnotetext{
Received for publication 27 May 2010. Accepted for publication 7 Sept. 2010.

We thank the University of Tehran and the Iran National Science Foundation (INSF) for providing support for this research. Dr. Alireza Nabipour is also acknowledged for kindly pre-reviewing the manuscript.

${ }^{1}$ To whom reprint requests should be addressed; e-mailkvahdati@ut.ac.ir.
}

bearing, shell seal, percent light-colored kernels, kernel veins, and kernel spots. Lateral bearing showed a fairly strong positive correlation with yield despite the large measurement error associated with yield.

Germain (1990) found that lateral bearing habit was moderately correlated with early leafing, tree architecture, and precocity. Solar et al. (2001) also found that lateral flowering trees developed flowers earlier in the spring and had better yield potential than terminal bearers. Leafing date was correlated with flower timing in addition to tree vigor, branching density, height of tree, and trunk diameter. Tree vigor was positively correlated with tree height, trunk diameter, tree form, branching density, and fruit bearing type. Forde and McGranahan (1996) reported a negative correlation between tree height and yield.

In contrast, Atefi (1990) found a strong positive correlation of yield with tree diameter and height but a negative correlation with nut weight. Altitude was positively correlated with frost resistance but negatively impacted yield.

Eskandari et al. (2006) studied genetic diversity and heritability of horticultural characteristics of 81 walnut genotypes from eight provinces of Iran. Broad sense heritabilities $\left(\mathrm{h}^{2}{ }_{\mathrm{b}}\right)$ for all traits were more than 0.60 with the exception of susceptibility to spring frost and kernel percentage, which were 0.45 and 0.39 , respectively.

Reported correlations of yield with protogynous or protandrous flowering habit conflict (Kornienko, 1974; Majacka, 1971). Sen (1985) obtained a negative significant correlation between shell thickness and kernel percentage. Akca and Sen (1997) found that nut and kernel weights and kernel to shell ratio of protogynous varieties were greater than those of protandrous types. Sharma and Sharma (2001) also reported correlations of nut traits. Correlations for traits of walnut were also reported by Komanich (1980), Sharma (1996), and Sholokhov (1974).

The coefficient of correlation is not informative in all cases in explaining cause-andeffect relationships in the variables, because the association between two variables may depend on a third variable. The use of path analysis provides a plausible explanation of observed correlations by modeling the cause-and-effect relations between the variables. Thus, it is possible to analyze the correlation coefficient of variables in the form of variance and covariance using path analysis (Okut and Orhan, 1993).

Path analysis has emerged as a general statistical method for cause-and-effect analysis in a system of correlated variables. A path coefficient is a standardized partial regression coefficient and measures the direct influence of a predictor variable on the response (dependent) variable (Mohammadi et al., 2003; Steel and Torrie, 1980). This permits the separation of the correlation coefficient into direct effect (path coefficient) and indirect effects (effects exerted through other independent variables) (Mohammadi et al., 2003). Unexplained effects are treated as residual effects. Path analysis provides both flexibility and greater insight into the biological organization of the organism than regression analysis. A comprehensive account of the method is given in Rao and Morton (1980). Path analysis has been used by plant breeders to understand the relationship between productivity and its components in various crop plants (Kang et al., 1983). This technique, however, has rarely been used in plant population biology and we did not find any report using path analysis in walnut.

The objectives of this study were: 1) to determine the correlations between agronomical traits of walnut in landraces of Kerman Province, Iran; and 2) to use causal (path) analysis to examine the influence of other horticultural traits on kernel percentage and blight susceptibility.

\section{Materials and Methods}

Seventy-one native walnut genotypes were selected from six valleys in Kerman province; Hanza (lat. $29.17^{\circ} \mathrm{N}$, long. $57.11^{\circ} \mathrm{E}$ ), Bezenjan (lat. $29.14^{\circ} \mathrm{N}$, long. $56.41^{\circ} \mathrm{E}$ ), Gougher (lat. $29.27^{\circ} \mathrm{N}$, long. $56.37^{\circ} \mathrm{E}$ ), Rien (lat. $29.21^{\circ}$ $\mathrm{N}$, long. $57.19^{\circ} \mathrm{E}$ ), Bidkhan (lat. $29.37^{\circ} \mathrm{N}$, long. $59.30^{\circ} \mathrm{E}$ ), and Kiskan (lat. $29.21^{\circ} \mathrm{N}$, long. $56.38^{\circ} \mathrm{E}$ ). These areas are situated at elevations of $2680,255,2815,2230,2525$, and $2580 \mathrm{~m}$ above mean sea level, respectively, and are the major centers for Persian walnut diversity. 
Twenty-one horticultural traits were evaluated during 2004-2007 based on Biodiversity International (IPGRI, 1994) descriptors (Table 1) and Pearson's coefficient of correlation was calculated (Steel and Torrie, 1980). Two main traits, kernel percentage and blight susceptibility, were analyzed as dependent variables and traits influencing these were detected by stepwise regression (Draper and Smith, 1998). Direct (standardized partial regression coefficients) and indirect effects of the influencing variables were then calculated using path analysis.

Based on the results of the stepwise regression analysis for kernel percentage, this trait was selected for use as a dependent variable in the path analysis and the traits that had a linear relationship with kernel percentage in stepwise regression, including shell thickness, tree form, difficulty of extracting kernels halves, nut weight, kernel weight, number of leaflets per leaf, shell texture, and kernel plumpness were treated as exogenous variables. The path diagram for kernel percentage is indicated in Figure 1A. Stepwise regression for blight susceptibility also indicated its use as a dependent variable in path analysis with flowering habit, nut shape, and leafing date treated as exogenous variables. The path diagram for blight susceptibility is shown in Figure 1B. Correlation analysis and stepwise regression were performed using SAS (Version 9.0; SAS Institute Inc., 1988) software. Also, the direct effects of exogenous variables on dependent variables were estimated by Proc Reg of SAS (Version 9.0) software using the unweighted least square method and stb (standardized b) option. Indirect effects involved the product of a correlation coefficient between two predictor variables and the appropriate direct effect in accordance with the path diagram (Williams et al., 1990; Wilson et al., 1981). Path diagrams were drawn using SPSS Amos 16 software (SPSS Inc., Chicago, IL).

\section{Results}

Correlation coefficients. Correlations between horticultural traits are shown in Table 2 . Tree form (more spreading) was positively correlated with lateral flowering habit (0.383), yield (0.294), and susceptibility to winter cold damage (0.336). Lateral-bearing trees had more yield and greater kernel weight than terminal bearers ( 0.638 and 0.228 , respectively) but were more susceptible to cold damage and blight $(0.526$ and 0.496$)$ and slightly more likely to be protandrous.

Blight-susceptible genotypes produced higher kernel weights but were also susceptible to winter cold. Susceptibility to cold damage was correlated with rough shell texture and greater nut weight. Leafing date was positively correlated with harvest date $(0.370)$ and date of leaf drop (0.298) but negatively correlated with kernel plumpness $(-0.254)$. Harvest date was correlated with date of leaf drop (0.603) and shell thickness (0.231) but negatively correlated with the difficulty of
Table 1. The horticultural traits evaluated and their scaling in 71 walnut genotypes native to Iran.

\begin{tabular}{|c|c|}
\hline The traits & Scaling \\
\hline 1. Tree form & $\begin{array}{l}\text { Upright (1), moderately upright (3), moderately spreading (5), } \\
\text { spreading (7) }\end{array}$ \\
\hline 2. Tree vigor & Very weak growth (1) to very vigorous $(9)$ \\
\hline 3. Flowering habit & $\begin{array}{l}\text { Terminal bearing (1), less than } 25 \% \text { lateral bearing (3), } 25 \% \text { to } 50 \% \\
\text { lateral bearing (5), more than } 50 \% \text { lateral bearing ( } 7 \text { ) }\end{array}$ \\
\hline 4. Leafing date & $\begin{array}{l}\text { Genotypes ranked from } 1 \text { to } 8 \text { in relation to the average walnut } \\
\text { leafing date within a location: greater than } 26 \mathrm{~d} \text { before } \\
\text { average (1) to } 21 \text { to } 25 \mathrm{~d} \text { after average }(8)\end{array}$ \\
\hline $\begin{array}{l}\text { 5. Numbers of leaflets per } \\
\text { leaf }\end{array}$ & From 1 ( 3 to 5 leaflets) to 4 ( 12 to 14 leaflets) \\
\hline 6. Dichogamy & Protandrous (1), homogamous (2), protogynous (3) \\
\hline 7. Catkin abundance & $\begin{array}{l}\text { No male flowers (1), few (3), average (5), abundant (7), very } \\
\text { abundant (9) }\end{array}$ \\
\hline 8. Harvest date & Very early (1) to extremely late (7) \\
\hline 9. Yield & No crop (1), commercially acceptable crop (4), very heavy yield (6) \\
\hline 10. Leaf drop date in fall & Early (3), moderate (5), late (7) \\
\hline 11. Blight susceptibility & Five classes: from very low (1) to very high (5) \\
\hline 12. Winter cold damage & Low damage (1), moderate damage (3), extensive damage (5) \\
\hline 13. Nut shape & $\begin{array}{l}\text { Round (1), triangular (2), broadly ovate (3), ovate (4), short } \\
\text { trapezoid (5), long trapezoid (6), broad elliptic (7), elliptic (8) }\end{array}$ \\
\hline 14. Shell texture & Smoothest (1) to roughest (9) \\
\hline 15. Shell thickness & Very thin (1), thin (3), moderate (5), thick (7), very thick (9) \\
\hline $\begin{array}{l}\text { 16. Difficulty in extracting } \\
\text { kernel halves }\end{array}$ & Very difficult (1) to very easy (9) \\
\hline 17. Kernel plumpness & Shriveled (3) to very plump (9) \\
\hline 18. Kernel color & Brown (1), amber (3), light amber (5), light (7), and extra light (9) \\
\hline 19. Nut weight in grams & From 1 (less than $8.5 \mathrm{~g}$ ) to 9 (greater than $15.5 \mathrm{~g}$ ) \\
\hline 20. Kernel weight in grams & From 1 (less than $3.5 \mathrm{~g}$ ) to 7 ( 5.5 to $6.49 \mathrm{~g}$ ) \\
\hline 21. Kernel percentage & Ratio of kernel weight to nut weight $\times 100$ \\
\hline
\end{tabular}

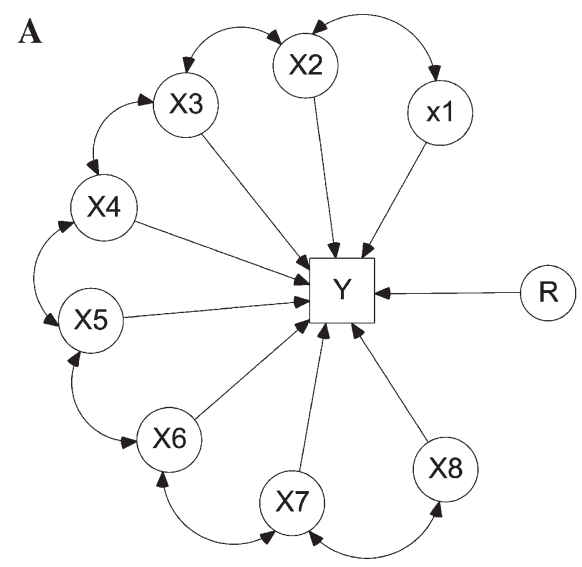

$\mathbf{B}$

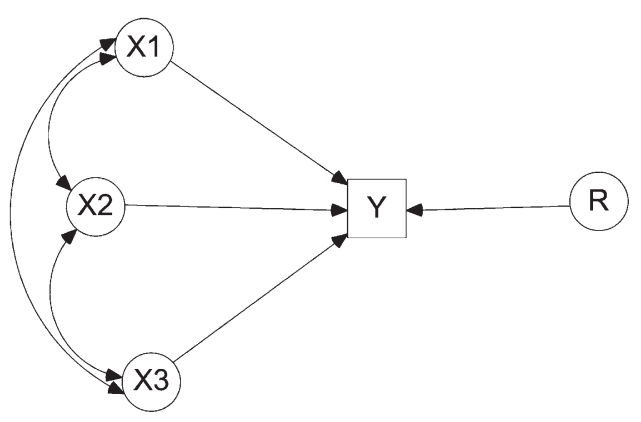

Fig. 1. Path diagram of effects of exogenous traits on kernel percentage (A) and blight susceptibility (B). Curved double-headed arrows show correlation coefficients and straight arrows show direct effects. Indirect effects are obtained by multiplying a correlation coefficient between two exogenous variables and the appropriate direct effect. (A) $\mathrm{Y}=$ kernel percentage; $\mathrm{X} 1=$ shell thickness; $\mathrm{X} 2=$ tree form; $\mathrm{X} 3$ = difficulty in extracting kernel halves; $\mathrm{X} 4=$ nut weight; $\mathrm{X} 5=$ kernel weight; $\mathrm{X} 6=$ numbers of leaflets per leaf; X7 = shell texture; X8 = kernel plumpness; $\mathrm{R}=$ residual effects. In $\mathbf{A}$, all of the exogenous traits have pairwise correlations, but only the correlations between the neighbor traits are shown. (B) $\mathrm{Y}=$ blight susceptibility; $\mathrm{X} 1$ = flowering habit; $\mathrm{X} 2$ = nut shape; $\mathrm{X} 3$ = leafing date; $\mathrm{R}=$ residual effects. 


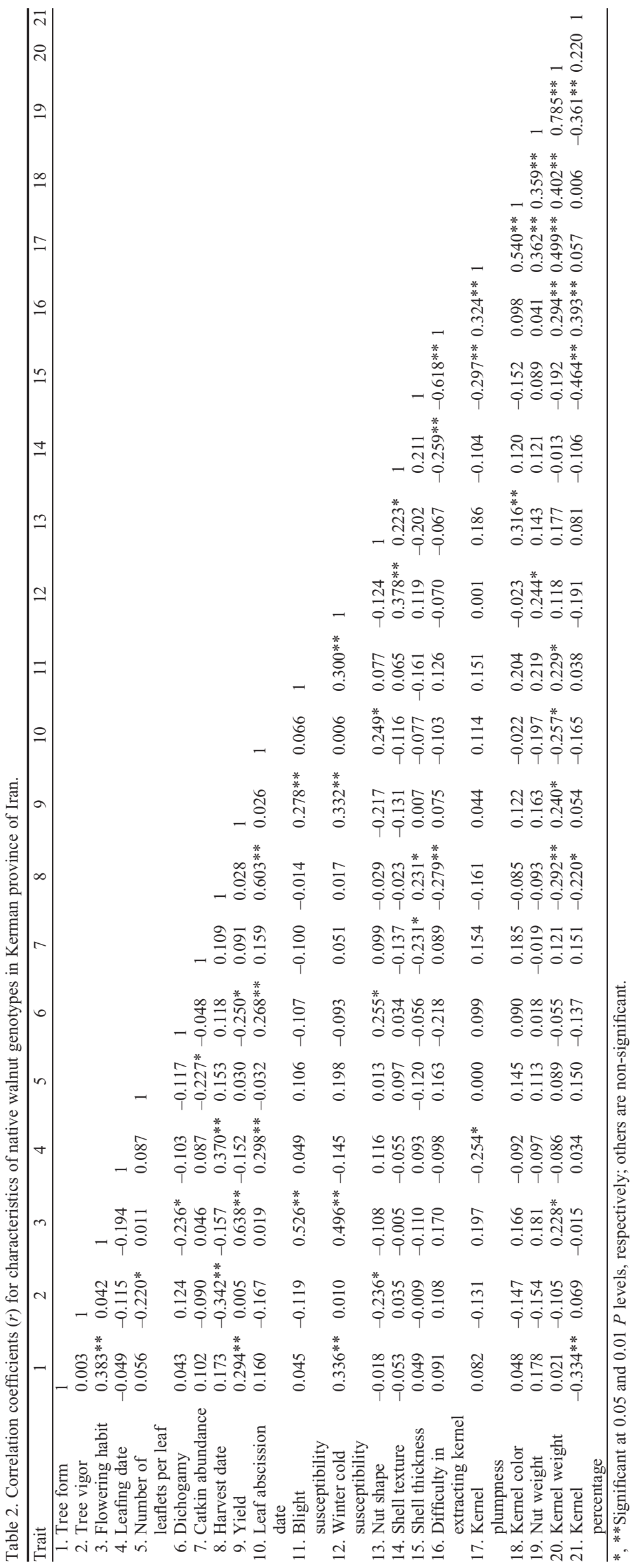

extracting kernel halves and kernel weight $(-0.279$ and -0.292 , respectively).

Nut and kernel weights correlated positively (0.785), but nut weight and kernel percentage were negatively related $(-0.361)$. Shell thickness was negatively correlated with difficulty in extracting kernel halves, kernel plumpness, and kernel percentage. Kernels with the lightest color had the greatest nut and kernel weights and kernel plumpness also correlated with these traits.

Stepwise regression and path coefficient analyses. After calculating the correlation coefficients, two main horticultural traits, kernel percentage and blight susceptibility, were considered as dependent variables and important independent variables were determined using stepwise regression (Tables 3 and 4). Then the direct and indirect effects of each independent variable on the two key traits were calculated (Tables 5 and 6). Stepwise regression showed that kernel weight, shell thickness, tree form, difficulty in extracting kernel halves, nut weight, number of leaflets per leaf, shell texture, and kernel plumpness accounted $32.39 \%, 26.49 \%, 12.62 \%, 4.80 \%$, $4.66 \%, 3.13 \%, 1.85 \%$, and $1.79 \%$, respectively, of the variations in kernel percentage, although shell thickness was then removed in Step 6 from the regression model. As shown in Table 3, shell thickness was the first variable that entered to the model. Nonetheless, regression coefficients of shell thickness and difficulty of extracting kernel halves were not significant after the entrance of kernel weight into the model in Step 5. Because the regression coefficient for shell thickness was lower than that for difficulty in extracting kernel halves, the former trait was removed from the model in Step 6 (Table 3). In the stepwise regression for blight susceptibility, only three traits, flowering habit, nut shape, and leafing date, were entered into the model and explained $\approx 35.3 \%$ of the variations in blight susceptibility. Nut shape and leafing date coefficients were not significant at Step 3 (Table 4).

Comparison of direct and indirect effects on kernel percentage (Table 5) shows that kernel weight and difficulty in extracting kernel halves had the greatest positive direct effects $(0.812$ and 0.521$)$ and shell thickness and nut weight had the most negative direct effects $(-0.541$ and -0.836$)$.

Stepwise regression of blight susceptibility data showed that flowering habit, nut shape, and leafing date accounted for $29.61 \%, 2.89 \%$, and $2.8 \%$ of the variation (Table 4 ) and path analysis showed these traits all had positive direct effects (Table 6).

\section{Discussion}

The positive significant correlation of tree form with flowering habit and winter cold susceptibility indicates that trees with a more spreading (less upright) form are more likely to be both lateral flowering and susceptible to winter cold. Germain (1990) and Solar et al. (2001) found a similar relationship between tree form and lateral flowering. 
Table 3. Stepwise regression between kernel percentage (dependent variable) and other traits (independent variables) in native Persian walnut genotypes of Kerman, Iran.

\begin{tabular}{|c|c|c|c|c|c|c|c|c|c|c|c|c|}
\hline Step & Inserted variable & $\mathrm{a}^{\mathrm{z}}$ & b1 & $\mathrm{b} 2$ & b3 & b4 & b5 & $\mathrm{b} 6$ & $\mathrm{~b} 7$ & $\mathrm{~b} 8$ & Final $R^{2}$ & Partial $R^{2}$ \\
\hline 2 & Tree form & $65.33^{* *}$ & $-2.138 * *$ & $-1.177^{* *}$ & & & & & & & $0.3911 * *$ & 0.1262 \\
\hline 3 & $\begin{array}{l}\text { Difficulty in } \\
\text { extracting kernel }\end{array}$ & $53.83 * *$ & $-1.36^{*}$ & $-1.32 * *$ & $1.454 *$ & & & & & & $0.4391 *$ & 0.048 \\
\hline 5 & Kernel weight & $46.55^{* *}$ & $-0.424 \mathrm{NS}$ & $-0.605 * *$ & $0.663 \mathrm{NS}$ & $-2.69 * *$ & $6.303^{* *}$ & & & & $0.8096 * *$ & 0.3239 \\
\hline 6 & $\begin{array}{l}\text { Number of leaflets } \\
\text { per leaf }\end{array}$ & $40.48 * *$ & & $-0.616^{* *}$ & $0.75^{*}$ & $-2.97 * *$ & $6.853 * *$ & $1.773 * *$ & & & $0.8356^{* *}$ & 0.0313 \\
\hline
\end{tabular}

Table 4. Stepwise regression between blight susceptibility (dependent variable) and other traits (independent variables) in native Persian walnut genotypes of Kerman, Iran.

\begin{tabular}{llcccccc}
\hline Step & Inserted variable & $\mathrm{a}^{\mathrm{z}}$ & $\mathrm{b} 1$ & $\mathrm{~b} 2$ & $\mathrm{~b} 3$ & Final $R^{2}$ & Partial $R^{2}$ \\
\hline 1 & Flowering habit & $0.564^{* *}$ & $0.2164^{* *}$ & & & $0.2961^{* *}$ & 0.2961 \\
2 & Nut shape & $0.343 \mathrm{NS}$ & $0.228^{* *}$ & $0.057 \mathrm{NS}$ & & $0.325 \mathrm{NS}$ & 0.0289 \\
3 & Leafing date & $0.150 \mathrm{NS}$ & $0.2273^{* *}$ & $0.116 \mathrm{NS}$ & $0.058 \mathrm{NS}$ & $0.353 \mathrm{NS}$ & 0.028 \\
\hline
\end{tabular}

**Significant at $0.01 P$ level; NS = non-significant.

$\mathrm{z}_{\mathrm{a}}=$ intercept in each step; $\mathrm{b} 1$ = coefficient of flowering habit in each step; $\mathrm{b} 2=$ coefficient of nut shape in second step forward; $\mathrm{b} 3$ = coefficient of leafing date; Final $R^{2}=$ final coefficient of determination in each step and Partial $R^{2}=$ partial coefficient of determination in each step.

Table 5. Direct (bold numbers) and indirect effects of traits on kernel percentage in native Persian walnut genotypes of Kerman, Iran.

\begin{tabular}{lrrrrrrrrr}
\hline Character & 1 & \multicolumn{1}{c}{2} & \multicolumn{1}{c}{3} & 4 & \multicolumn{1}{c}{5} & \multicolumn{1}{c}{6} & \multicolumn{1}{c}{7} & \multicolumn{1}{c}{8} & \multicolumn{1}{c}{$\mathrm{r}_{\mathrm{p}}$} \\
\hline 1. Shell thickness & $\mathbf{- 0 . 5 4 1}$ & -0.005 & 0.169 & -0.077 & -0.157 & 0.002 & 0.045 & 0.099 & -0.464 \\
2. Tree form & -0.027 & $\mathbf{- 0 . 0 8 6}$ & -0.048 & -0.154 & 0.017 & 0 & -0.012 & -0.028 & -0.334 \\
3. Difficulty in extracting & -0.176 & 0.007 & $\mathbf{0 . 5 2 1}$ & -0.036 & 0.238 & 0.001 & -0.057 & -0.109 & 0.394 \\
$\quad$ kernel halves & & & & & & & & & \\
4. Nut weight & -0.049 & -0.016 & 0.021 & $-\mathbf{0 . 8 6 3}$ & 0.637 & 0.001 & 0.026 & -0.122 & -0.361 \\
5. Kernel weight & 0.103 & -0.002 & 0.153 & -0.678 & $\mathbf{0 . 8 1 2}$ & 0 & -0.003 & -0.168 & 0.22 \\
6. Number of leaflets & 0.065 & -0.005 & 0.085 & -0.097 & -0.072 & $\mathbf{0 . 0 0 9}$ & 0.021 & 0 & 0.15 \\
$\quad$ per leaf & & & & & & & & & \\
7. Shell texture & -0.114 & -0.004 & -0.136 & -0.105 & -0.011 & 0 & $\mathbf{0 . 2 1 7}$ & 0.034 & -0.107 \\
8. Kernel plumpness & 0.176 & -0.017 & 0.193 & -0.273 & 0.349 & 0 & -0.024 & $-\mathbf{0 . 3 4 9}$ & 0.057 \\
\hline Residual effects =0.258 & & & & & & & & &
\end{tabular}

Residual effects $=0.258$

Table 6. Direct (bold numbers) and indirect effects of traits on the blight susceptibility of native Persian walnut genotypes in Kerman, Iran.

\begin{tabular}{lcrrc}
\hline Character & 1 & \multicolumn{1}{c}{2} & \multicolumn{1}{c}{3} & $\mathrm{r}_{\mathrm{p}}$ \\
\hline 1. Flowering habit & $\mathbf{0 . 5 6 7}$ & -0.014 & -0.029 & 0.526 \\
2. Nut shape & -0.062 & $\mathbf{0 . 1 2 1}$ & 0.016 & 0.076 \\
3. Leafing date & -0.11 & 0.014 & $\mathbf{0 . 1 4 5}$ & 0.049 \\
\hline Residual effects $=0.827$. & & &
\end{tabular}

We also found that lateral-bearing trees were more likely to be high-yielding than terminal bearers, as also reported by Hansche et al. (1972), and to have higher kernel weights, but this advantage could be offset in cold locations by their greater susceptibility to winter cold damage. Although they were lower-yielding, upright trees produced nuts with somewhat greater kernel percentages. The observed positive and significant correlation of flowering habit with yield and kernel weight can be useful in the selection process for breeding programs as suggested by Hansche et al. (1972) who noted that the low heritability of yield (0.07), the relatively high heritability of flowering habit (0.40), and the positive correlation coefficient between the two in their data indicated that screening trees on the basis of flowering habit (more lateral bearing trees) would lead to selecting highyielding trees.

We found a positive correlation between leafing date and harvest date, which is in agreement with Forde and McGranahan (1996) and Hansche et al. (1972). Protandrous genotypes had higher yields and more rounded fruit shape than protogynous ones. This result agrees with Kornienko (1974), but Akca and Sen (1997) and Majacka (1971) reported the reverse.

The correlations of kernel plumpness with nut and kernel weight and kernel color were significant at the $1 \%$ probability level, although Eskandari et al. (2006) reported a significant negative correlation for these traits. This difference could be the result of the geographic distribution of genotypes studied. The earlier study included genotypes from high mountain areas in different provinces of Iran.

Yield is a main objective in most Juglans regia breeding programs. This trait was positively correlated with lateral bearing, blight susceptibility, susceptibility to winter cold, and kernel weight in our study. This suggests that selecting for yield may increase winter cold damage and blight. This correlation is important because the heritability of susceptibility to winter cold and blight is relatively high (Eskandari et al., 2006), whereas that of the yield is very low (Hansche et al., 1972).

The positive correlation between yield and kernel weight has important commercial and practical implications because both traits are desirable in developing new cultivars.

The correlation between harvest date and date of leaf drop, in addition to the high heritability of harvest date 0.85 estimated by Eskandari et al. (2006), indicates that selection for late harvest date would also select for late-season leaf abscission and consequently susceptibility to fall frost damage.

Our results indicate that it will be easier to extract kernels in halves from genotypes with smooth shell texture (negative correlation, -0.26). In contrast, Eskandari et al. (2006) reported a small positive, but not significant, correlation (0.195) between shell texture and difficulty in extracting kernel halves. Nuts with thicker shells had both a lower kernel percentage and kernels that were less plump. These results are similar to those described by Eskandari et al. (2006), Sen (1985), and Sharma and Sharma (2001).

The positive correlation of nut weight with kernel weight $(0.785)$ and the negative correlation with kernel percentage $(-0.361)$ were in agreement with Eskandari et al. (2006) and Sharma and Sharma (2001). Hansche et al. (1972) also reported a positive correlation between nut weight and kernel weight.

Finally, kernel color was positively correlated with nut and kernel weight. Atefi (1990) reported the same result in elevated regions. This is an important correlation because light kernel color is a primary breeding objective for walnut (Tulecke and McGranahan, 1994).

In developing the regression model for kernel percentage, shell thickness was entered in the first step, but after entrance of difficulty in extracting kernel halves and kernel weight, shell thickness was eliminated from the model. This means that if kernel weight and difficulty in extracting kernel halves are considered in the model, shell thickness does not need to be included. However, when we examined the raw data for the 71 genotypes scored for shell thickness, 16 were scored thin (Score 3), one very thick (Score 9), and none very thin (Score 
1). Examination of the data for difficulty in extracting kernels in halves showed that none were scored as very easy (Score 9) or very difficult (Score 1). We concluded that the indicated elimination of shell thickness from the model could be an artifact related to uneven representation of these traits in the particular genotypes included. Therefore, we did not eliminate shell thickness from the path analysis.

The stepwise regression model for blight susceptibility showed that the traits entered into the model explained only approximately one-third of the variation in blight scoring with nut shape and leafing date showing little effect and their coefficients not significant. This indicates that other factors that were not considered in the study play a more important role in explaining blight.

Comparison of direct and indirect effects indicates that nut and kernel weight had interactive effects on kernel percentage, i.e., the nut weight reduced the kernel percentage directly but increased the kernel percentage indirectly through its effect on kernel weight.

In conclusion, we found that four key variables, kernel weight, nut weight, shell thickness, and difficulty in extracting kernel halves, were the main variables accounting for kernel percentage and that they should be considered together in breeding. Path analysis showed that flowering habit, nut shape, and leafing date had positive direct effects on blight susceptibility. Among these, flowering habit had more effect than the other two.

The residual effects indicate the degree to which the causal factors account for variation in the dependent factor. Low residual effects show that the causal factors explain the dependent variable well. In the present study, these were estimated to be 0.827 for blight susceptibility and 0.258 for kernel percentage. Because the residual effects for blight susceptibility were relatively high and a low coefficient of determination was observed in the stepwise regression, we can conclude that there are important additional factors influ- encing blight susceptibility that were not considered in this study.

\section{Literature Cited}

Akca, Y. and S.M. Sen. 1997. The relationship between dichogamy and yield-nut characteristics in Juglans regia L. Acta Hort. 442:215-216.

Atefi, J. 1990. Preliminary research of Persian walnut and correlation between pair characters. Acta Hort. 284:97-104.

Draper, N.R. and H. Smith. 1998. Applied regression analysis. 3rd Ed. John Wiley and Sons, New York, NY.

Eskandari, S., D. Hassani, and A. Abdi. 2006 Investigation on genetic diversity of Persian walnut and evaluation of promising genotypes. Acta Hort. 705:159-166.

Fjellstrom, R.G. and D.E. Parfitt. 1994. Walnut (Juglans spp.) genetic diversity determined by restriction fragment length polymorphisms. Genome 37:690-700.

Forde, H.I. and G.H. McGranahan. 1996. Walnuts, p. 241-274. In: Janick, J. and N. Moore (eds.). Fruit breeding. Vol.3, Nuts. John Wiley and Sons, Inc, New York, NY.

Germain, E. 1990. Inheritance of late lateral bud fruitfulness in walnut (Juglans regia $\mathrm{L}$.), phenotypic correlation among some traits of the tree. Acta Hort. 248:125-134.

Hansche, P.E., V. Beres, and H.I. Forde. 1972. Estimates of quantitative genetic properties of walnut and their implications for cultivar improvement. J. Amer. Soc. Hort. Sci. 97:279-285.

IPGRI. 1994. Descriptors for walnut (Juglans spp.). International Plant Genetics Resources Institute, Rome, Italy

Kang, M.S., J.D. Miller, and P.Y.P. Tai. 1983. Genetic and phenotypic path analysis and heritability in sugar cane. Crop Sci. 23:643-647.

Komanich, I.G. 1980. Correlation between walnut fruit characters in a seed population. Bull Acad. Sci. RSS Mold. 2:27-30.

Kornienko, N.A. 1974. Types of dichogamy in walnut. P1. Br. Ab. 44:452.

Majacka, A.D. 1971. Dichogamy and fertility in walnut. P1. Br. Ab. 41:186.

Mohammadi, S.A., B.M. Prasanna, and N.N. Singh. 2003. Sequential path model for determining interrelationship among grain yield and related characters in maize. Crop Sci. 43:1690-1697.
Okut, H. and H. Orhan. 1993. Path Analizi and Korelasyon Katsayis1. 1.Ulusal Ekonometri ve Istatistik Sempozyumu. 11-12 Kasım Izmir.

Rao, D.C. and N.E. Morton. 1980. Path analysis of quantitative inheritance, p. 355-372. In: Meieke, J.H. and M.H. Crawford (eds.). Developments in anthropological genetics. Vol. 1. Theory and methods, Current Plenum Press, New York, NY.

SAS Institute Inc. 1988. SAS Stat user's guide. SAS Institute Inc., Cary, NC.

Sen, S.M. 1985. Correlations between shell thickness, shell cracking resistance, shell seal and shell upright cracking resistance and some other fruit quality characters in walnut (Juglans regia L.). Doga. Bilim Dergisi. 9:10-24.

Sharma, O.C. 1996. Variability in seedling trees of Persian walnut in Solan area of Himachal Pardesh. MSc thesis, Solan UHF University.

Sharma, O.C. and S.D. Sharma. 2001. Genetic divergence in seedling trees of Persian walnut (Juglans regia $\mathrm{L}$.) for various metric nut and kernel characters in Himachal Pradesh. Sci. Hort. 88:163-171.

Sholokhov, L.V. 1974. Quality characters of fruit in walnut and correlation between them. Tr. Novocherkas. Inzha Melior. Inta 13:106-112.

Solar, A., M. Hudina, and F. Stampar. 2001. Relationship between tree architecture, phenological data and generative development in walnut (Juglans regia L.). Acta Hort. 544: 275-285.

Steel, R.G.D. and J.H. Torrie. 1980. Principles and procedures of statistics, a biometrical approach. McGraw Hill, New York, NY.

Tulecke, W. and G.H. McGranahan. 1994. The walnut germplasm collection at the University of California, Davis: A description of the collection and a history of the breeding program of E.F. Serr and H.I. Forde (eds.). Report 13. Univ. Calif. Genetic Resources Conservation Program, Davis, CA.

Vahdati, K. 2000. Walnut situation in Iran. NucisNewsletter. 9:32-33.

Williams, W.A., M.B. Jones, and M.W. Demment. 1990. A concise table for path analysis statistics. Agron. J. 82:1022-1024.

Wilson, A.M., R.L. Cuany, J.G. Fraser, and W.R. Oaks. 1981. Relationships among components of seed yield in blue Grama. Agron. J. 73:10581062 . 